\title{
COMMENTARY
}

\section{To dose or not to dose: that is the (starch) question ...}

\author{
Lewis J Kaplan* \\ See related research by Boussekey et al., http://ccforum.com/content/14/2/R40
}

\begin{abstract}
The present study describes the impact on renal function of a modern starch used for resuscitation in the intensive care unit. The role of starch in renal dysfunction, the importance of the definition of acute kidney injury and acute renal failure, and hyperoncoticity are reviewed.
\end{abstract}

Hydroxyethyl starch (HES) has been vilified, praised, or largely ignored as a resuscitation fluid depending on the setting within which the HES is administered. The most recent HES focus has been on renal injury when HES is administered to patients with severe sepsis or septic shock. Boussekey and colleagues have provided us with a single-center, 2-year view of how HES use in the intensive care unit relates to renal function [1]. Several elements of this study merit discussion.

First, Boussekey and colleagues' study is similar to another that provided a snapshot view of fluid resuscitation in a host of European intensive care units [2]. Most notably, HES use was not associated with renal injury even when administered to patients with sepsis. This finding reflects a relatively low dose of HES, consistent with that used in the current study - quite different from the doses used in studies decrying the use of HES [3-5].

Like the study of Sakr and colleagues [2], HES was only one component of a multimodal approach to fluid management. This critical element underscores the observation that HES does not provide significant free water. Resuscitation with only HES (as predominantly occurs in HES trials) will therefore establish a hyperoncotic state and predictably lead to acute kidney injury (AKI) or acute renal failure (ARF) [6].

Third, the authors are to be congratulated on applying an objective and evidence-based approach to categorizing renally relevant events - the RIFLE criteria [7]. Most

*Correspondence: lewis.kaplan@yale.edu

330 Cedar St, BB-310, New Haven, CT 06518 USA trials evaluating renal dysfunction are binary, in that ARF is present or absent; AKI is often not addressed. Moreover, the definitions used in non-RIFLE trials are often based on a percentage change in creatinine (100\%), a creatinine threshold $(>2.0 \mathrm{mg} \%)$, and the need for dialysis regardless of modality without specifying the triggering criteria. Worse still, the HES and diluents used are vastly different between trials.

Boussekey and colleagues used a modern low molecular weight and degree of substitution starch, and the diluent was not specified but presumed to be $0.9 \%$ normal saline solution. Unfortunately, they did not report on the presence of hyperchloremic metabolic acidosis during their trial, a condition that is associated with reduced renal blood flow and reduced glomerular filtration rate. Patients in the study were divided into two groups based on whether HES was or was not administered at any time. Despite having administered HES to a more ill patient population with more shock (septic in particular), more vasopressor use, and more surgery and anesthesia exposure, the incidence of AKI or ARF was no different between the two groups. This is a key message for those who, at least, use the same HES.

It is likely that the authors' findings are applicable to other groups, as Sakr and colleagues' study used a different HES to that used in this trial. Moreover, it would be appropriate to use the data from this trial as another impetus to re-examine our assumptions about HES in different settings. Much of the thoughts around HES and AKI or ARF stem from renal biopsy in those patients with ARF after having received HES. We do not, however, biopsy those patients without AKI/ARF who have received HES. We thus do not know the likelihood of having HES deposition and persistence in renal tubules in the absence of AKI/ARF. Furthermore, in the phase III US Food and Drug Administration registration trial of a large molecular weight and high degree of substitution starch in the US, much larger doses than used in the present trial (upwards of 5,000 cc) were not associated with any renal dysfunction [8]. One must wonder whether the data cited to establish a HES moratorium are conditionally specific to sepsis, to an artifact of hyperoncoticity, to an effect of the starch diluent, or to some combination. 
Whether different starches, starch diluents, or other crystalloids or colloids promote, abrogate, or ameliorate AKI in the critically ill or injured patient has been recently published [9]. Boussekey and colleagues have taken us another step down the path of understanding how colloids appropriately fit into the intensivists' armamentarium. Further research will be required to discern whether the excellent results the authors have obtained derive directly from the biophysical and biochemical properties of the starch itself, from the patient populations in which the HES is used, or from other factors such as the acid-base milieu into which the starch is placed. One element is clear from this manuscript - that the use of the RIFLE criteria allows one to employ an objective means to evaluate the impact of a particular therapy on renal function. Perhaps all manuscripts evaluating renal function should follow these authors' lead so that we may truly learn whether or not to dose.

\section{Abbreviations}

AKI, acute kidney injury; ARF, acute renal failure; HES, hydroxyethyl starch; RIFLE, risk, injury, failure, loss, and end-stage kidney disease.

\section{Competing interests}

The author declares that they have no competing interests.

Published: 6 May 2010

\section{References}

1. Boussekey N, Darmon R, Langlois J, Alfandari S, Devos P, Meybeck A, Chiche A, Georges H, Leroy O: Resuscitation with low volume hydroxyethylstarch $130 \mathrm{kDa} / 0.4$ is not associated with acute kidney injury. Crit Care 2010, 14:R40.
2. Sakr Y, Payen D, Reinhart K, Sipmann FS, Zavala E, Bewley J, Marx G, Vincent JL: Effects of hydroxyethyl starch administration on renal function in critically ill patients. Br J Anesth 2007, 98:216-224.

3. Schortgen F, Lacherade JC, Bruneel F, Cattaneo I, Hernery F. Lemaire F, Brochard L: Effects of hydroxyethyl starch and gelatin on renal function in severe sepsis: a multicentre randomized study. Lancet 2001, 357:911-916.

4. Brunkhorst FM, Engel C, Bloos F, Meir-Hellmann A, Ragaller M, Weiler N, Moerer O, Gruendling M, Oppert M, Grond S, Olthoff D, Jaschincki U, John S, Rossaint R, Welte T, Schaefer M, Kern P, Kuhunt E, Kiehntopf M, Hartog C, Nathanson C, Loeffler M, Rainhart K; German Competence Network Sepsis (SepNet): Intensive inslin therapy and pentastarch resuscitation in severe sepsis. N Engl J Med 2008, 358:125-139.

5. Honore PM, Joannes-Boyau O, Boer W: Hyperoncotic colloids in shock and risk of renal injury: enough evidence for a banning order? Intensive Care Med 2008, 34:2127-2129.

6. Schortgen F, Girou E, Deye N, Brochard L; CRYCO Study Group: The risk associated with hyperoncotic colloids in patients with shock. Intensive Care Med 2008, 34:2157-2168.

7. Bellomo R, Ronco C, Kellum JA, Mehta RL, Palevsky P; ADQI workgroup: Acute renal failure - definition, outcome measures, animal models, fluid therapy and information technology needs: the Second International Consensus Conference of the Acute Dialysis Quality Initiative (ADQI) Group. Crit Care 2004, 8:R204-R212.

8 Gan TJ, Bennett-Guerrero E, Phillips-Bute B, Wakeling H, Moskowitz DM, Olufolabi Y, Konstadt SN, Bradford C, Glass PS, Machin SJ, Mythen MG: Hextend, a physiologically balanced plasma expander for large volume use in major surgery: a randomized phase III clinical trial. Hextend Study Group. Anesth Analg 1999, 88:992-998.

9. Kellum JA, Cerda J, Kaplan L, Nadim MK, Palevsky PM: Fluids for prevention and management of acute kidney injury [review - ADQI Consensus Statement]. Int J Artif Organs 2008, 31:96-110.

doi:10.1186/cc8973

Cite this article as: Kaplan LJ: To dose or not to dose: that is the (starch) question ... Critical Care 2010, 14:148. 